\title{
O olhar complexo sobre a formação continuada de professores para a utilização pedagógica das tecnologias e mídias digitais
}

\section{The complex view on the continued training of teachers for the pedagogical use of digital technologies and media}

\author{
Taís Wojciechowski Santos* \\ Ricardo Antunes de Sá**
}

\begin{abstract}
RESUMO
O presente artigo apresenta os resultados de uma pesquisa de doutorado que teve por objetivo caracterizar, descrever, analisar, compreender e contrastar como se organizam os programas de formação continuada de professores em tecnologias e mídias digitais (TMDs), atuantes nas séries iniciais do Ensino Fundamental. A partir de uma abordagem qualitativa foi realizado um estudo de caso múltiplo, nos programas de formação continuada em TMDs propostos pelas Secretarias Municipais da Educação (SMEs) dos municípios de Curitiba (PR), Cascavel (PR), Florianópolis (SC) e Joinville (SC). Os dados foram obtidos por meio de entrevistas semiestruturadas, questionários e análise das diretrizes e currículos norteadores das ações educacionais destes quatro municípios. A análise e a compreensão do processo deram-se à luz dos pressupostos teóricos do Pensamento Complexo, de Edgar Morin. Os principais resultados obtidos com este estudo indicam: a relevância do protagonismo docente nos processos formativos; a necessidade de realização da formação in loco, na unidade de atuação dos professores; a importância de um acompanhamento, assessoramento e auxílio para que os docentes coloquem em prática os
\end{abstract}

* Secretaria Municipal da Educação de Curitiba. Curitiba, Paraná, Brasil. E-mail: taiswki@ gmail.com - https://orcid.org/0000-0002-6789-9773

** Universidade Federal do Paraná. Curitiba, Paraná, Brasil. E-mail: antunesdesa@gmail.com - https://orcid.org/0000-0001-5979-9265 
conteúdos desenvolvidos nas formações; a necessidade de infraestrutura adequada, com aquisição e manutenção de recursos digitais; e a pertinência da formação continuada de professores não ser desenvolvida de forma isolada, mas compreendida como uma tecitura de múltiplos elementos que precisam ser considerados, para que as práticas formativas em TMDs possam contribuir para o processo de qualificação docente.

Palavras-chave: Formação continuada de professores. Tecnologias e mídias digitais na educação. Pensamento Complexo.

\begin{abstract}
This article presents the doctoral research results that aimed to characterize, describe, analyze, understand, and contrast how programs for continuing education of teachers in technologies and digital media (TMDs), operating in the initial grades of Elementary Education, are organized. Based on a qualitative approach, a multiple case study was carried out in the continuing education programs in TMDs proposed by the Municipal Education Departments (SMEs) of the municipalities of Curitiba (PR), Cascavel (PR), Florianópolis (SC), and Joinville (SC). The data were obtained through semi-structured interviews, questionnaires, and guidelines and curricula analysis that guides the educational actions of these four municipalities. The investigation and understanding of the process took place in light of the Complex Thinking theoretical assumptions by Edgar Morin. The main results obtained with this study indicate: the relevance of the teaching role in training processes; the need to carry out training on the spot, in the unit where teachers work; the importance of monitoring, advice, and assistance for teachers to put into practice the content developed in training; the need for adequate infrastructure, with the acquisition and maintenance of digital resources; and the relevance of continuing teacher education should not be developed in isolation, but understood as a weave of multiple elements that need to be considered so that the training practices in TMDs can contribute to the teacher qualification process.
\end{abstract}

Keywords: Continuing Education of Teachers. Digital technologies and media in education. Complex Thinking. 


\title{
A formação continuada de professores para a utilização pedagógica das tecnologias e mídias digitais nos processos de ensino-aprendizagem
}

A formação continuada se constitui como um dos principais meios de aperfeiçoamento profissional. É um dos mais importantes caminhos para os professores adquirirem novos conhecimentos teóricos e práticos, a fim de aprimorar as suas práticas pedagógicas e desenvolver um processo de ensinoaprendizagem de qualidade.

Conforme versa Sacristán (1999) o conceito de formação continuada pode ser compreendido como perspectiva de mudança na prática docente, a partir da experimentação de ações inovadoras decorrentes da experiência de outros profissionais, tendo em vista o constante processo de intervenção e mudança na realidade de atuação do profissional que participa deste processo de formação.

Os processos formativos adquirem legitimidade na Lei de Diretrizes e Bases da Educação Nacional (LDB) n. 9.394/96 (BRASIL, 1996) no artigo 63, inciso III, que regulamenta a necessidade dos programas de formação continuada aos profissionais da educação em seus diversos níveis; e no parecer $\mathrm{CNE} / \mathrm{CP} \mathrm{n}$. $02 / 2015$, onde menciona que:

\begin{abstract}
A formação continuada compreende dimensões coletivas, organizacionais e profissionais, bem como o repensar do processo pedagógico, dos saberes e valores, e envolve atividades de extensão, grupos de estudos, reuniões pedagógicas, cursos, programas e ações para além da formação mínima exigida ao exercício do magistério na educação básica, tendo como principal finalidade a reflexão sobre a prática educacional e a busca de aperfeiçoamento técnico, pedagógico, ético e político do profissional docente (BRASIL, 2015, p. 34).
\end{abstract}

Segundo Freire (2004) para o desenvolvimento do trabalho docente, é fundamental que os professores se apropriem constantemente dos avanços da ciência e das teorias pedagógicas, a fim de agregar à sua profissão um profundo conhecimento das práticas docentes já existentes e daquelas que surgem a cada dia.

A dinâmica contemporânea mediada pela utilização das tecnologias e mídias digitais (TMDs) vem promovendo significativas alterações nas formas das pessoas se relacionarem com as informações e com o conhecimento, por meio ao acesso às redes digitais. Estas transformações apresentam ao contexto escolar novos desafios que necessitam da construção de novas práticas de 
ensino, novas concepções de educação e novas formas de fomentar a formação continuada de professores (GATTI; BARRETO, 2009).

Apesar da diversidade de aparatos tecnológicos digitais (computadores, internet, tablets etc.) já inseridos desde a década de 80, nas escolas brasileiras, constata-se que estes suportes tecnológicos ainda não são utilizados como meios capazes de promover significativas alterações nas práticas pedagógicas escolares. As tecnologias e mídias digitais, entendidas ainda como simples recursos didáticos, ainda não são utilizadas em todas as suas potencialidades pelos docentes, a fim de promover melhorias nos processos de ensino educacional (VALENTE, 2013).

Dados apresentados em pesquisas e em publicações realizadas nas últimas décadas vêm demonstrando que a utilização das TMDs no contexto educacional é um desafio ainda a ser conquistado (KENSKI, 2012). Os dados indicam que um dos principais motivos para que o uso das TMDs não traga alterações e até mesmo benefícios aos processos pedagógicos de ensino e aprendizagem, estão atreladas as dificuldades na apropriação docente para a utilização pedagógica das mídias digitais em suas práticas escolares (VOSGERAU, 2005). E, isto se deve ao fato da inexistência ou inadequada formação de professores para a utilização pedagógica das tecnologias, principalmente as digitais (KENSKI, 2012).

Autores como Belloni (2003), Fantin e Rivoltella (2012), e Freitas (2009), apontam, por meio de suas pesquisas, que a formação inicial não prepara os professores para a utilização pedagógica das tecnologias e mídias digitais em suas práticas escolares. O que provoca uma lacuna na formação destes profissionais, ao não contemplar uma área que faz parte da realidade docente e principalmente dos estudantes.

Neste sentido, a formação continuada de professores em TMDs consolidase como fundamental para promover a utilização dos aportes digitais nas práticas pedagógicas. Esta constatação ganha força quando se observa que muitas vezes o uso das tecnologias ocorre de maneira desarticulada da prática pedagógica, sem apresentar relação com o desenvolvimento do currículo escolar. Em muitos casos, a utilização da TMDs ainda configura-se como atividades estanques e desconexas das ações desenvolvidas em sala de aula (ALMEIDA; VALENTE, 2011).

Estudos realizados em diferentes países apontam que esta dificuldade em integrar as TMDs nas práticas pedagógicas está associada às tensões, desafios e conflitos provocados pela introdução dos meios digitais na escola (OFCOM, 2006; GREEN; HANNON, 2007 apud ALMEIDA; VALENTE, 2011). Isso ocorre principalmente, porque os estudantes convivem e fazem uso das tecnologias de maneira mais confortável e harmoniosa do que os professores, o que gera insegurança por parte dos docentes e não desperta o interesse em integrá-las na sua prática educacional (ALMEIDA; VALENTE, 2011). 
Neste contexto, é necessário que os professores compreendam que sua função educacional não é saber utilizar com propriedade todas as tecnologias existentes. Seu papel constitui-se em conhecer e utilizar as mídias digitais, de maneira que este uso possa favorecer o processo de ensino-aprendizagem, num processo colaborativo com os estudantes, onde o professor tem o domínio do conhecimento pedagógico, mas o conhecimento tecnológico pode ser adquirido conjuntamente com os estudantes no desenvolvimento das ações educacionais.

A utilização das TMDs nas práticas pedagógicas sob a perspectiva de uma concepção complexa tem por objetivo superar a fragmentação e dicotomia do processo de ensino-aprendizagem (MORIN, 2010; 2011). Além de favorecer a integração dos saberes no sentido de contribuírem para a inclusão digital, a emancipação do ser humano e para a construção de uma cibercidadania (LEMOS, 2013) de professores, de estudantes e da comunidade escolar, "com base no princípio de que ser cidadão significa estar alfabetizado em todas as linguagens" (BELLONI, 2012, p. 53), inclusive na linguagem tecnológica.

Complementando as argumentações até aqui apresentadas sobre o processo de integração das TMDs nas práticas pedagógicas escolares, é imprescindível enfatizar que o professor tem papel primordial como mediador da utilização destes recursos na escola.

A tecnologia por si só não tem como ser um diferencial nos processos de ensino-aprendizagem. Mas sim a atuação dos profissionais da educação, tendo em vista o uso pedagógico dos meios digitais, com o objetivo de proporcionar novos encaminhamentos didático-metodológicos e novas formas de ensinar e aprender. Desta maneira, a utilização das TMDs no contexto escolar terá o seu sentido consolidado de trazer às gerações presentes e futuras, aportes digitais que possam contribuir para a construção de novos conhecimentos (ALMEIDA; VALENTE, 2011; KENSKI, 2012).

Neste processo de transformações pessoais e metodológicas, oriundas da inserção das TMDs no contexto escolar, os docentes necessitam de ações formativas que orientem a sua prática profissional, uma vez que a promoção de um ensino de qualidade, requer uma adequada formação de professores (NÓVOA, 1992).

A formação docente para atuar em propostas educacionais contemporâneas é algo amplo, complexo e diferenciado dos processos formativos já praticados. Necessita da "[...] incorporação de uma nova postura profissional, outra cultura, novos conceitos e novas práticas pedagógicas” (KENSKI, 2013, p. 94). Justifica-se, então, a relevância da existência de programas de formação de professores que contemplem subsídios teóricos, técnicos e metodológicos capazes de conduzir, orientar e acompanhar os profissionais no processo pedagógico de inserção das tecnologias e mídias digitais. 
É fundamental considerar que os processos formativos não devem se restringir apenas à disseminação de informações sobre o uso pedagógico das tecnologias e mídias digitais. É necessário ir além desta perspectiva, apresentando subsídios aos docentes para que adquiram conhecimentos técnicos sobre o uso do computador e compreendam o "porquê" e como integrar as TMDs na proposta curricular e nas práticas pedagógicas desenvolvidas no contexto escolar (VALENTE, 2001).

A intensificação em qualificar os cursos envolvendo as TMDs se faz necessária, uma vez que pesquisas científico-acadêmicas demostram que os professores melhor preparados, sentem maior segurança para usar as tecnologias digitais em suas práticas pedagógicas. Os programas de formação continuada que prezam pela qualidade do uso pedagógico das TMDs precisam investir em estratégias formativas que possibilitem ao professor o conhecimento necessário para utilizar os suportes tecnológicos digitais (computador, internet, tablets etc.), em diferentes atividades pedagógicas, com o objetivo de favorecer o processo de ensino-aprendizagem dos estudantes (KENSKI, 2012).

\section{As contribuições do Pensamento Complexo para a formação docente em tecnologias e mídias digitais}

Os pressupostos teóricos do Pensamento Complexo do filósofo e sociólogo francês Edgar Morin, abrem a possibilidade para novas formas de pensar, que considerem a importância da teia de relações dos fenômenos estudados, numa relação de interdependência entre o objeto de conhecimento e seu contexto. Para Morin (2008), a complexidade pode ser compreendida como:

[...] um tecido (complexus: o que é tecido junto) de constituintes heterogêneas inseparavelmente associadas: ela coloca o paradoxo do uno e do múltiplo. Num segundo momento, a complexidade é efetivamente o tecido de acontecimentos, ações, interações, retroações, determinações, acasos, que constituem nosso mundo fenomênico (MORIN, 2008, p. 20).

É um pensamento que visa à religação dos saberes, em oposição a uma visão simplificadora, disjuntiva e reducionista "[...] sem deixar de conviver com a solidariedade dos fenômenos existentes" (PETRAGLIA, 2000, p. 10). É uma 
tecitura que compreende como inseparáveis a pessoa e a sociedade; o professor e o aluno; o sujeito e o objeto; a ordem e a desordem; e todos os demais fatos e acontecimentos que regem e tecem a trama da vida (MORAES, 2010).

É importante compreender que o Pensamento Complexo propõe uma reforma na maneira de pensar, ou seja, uma nova construção do pensamento (MORIN, 2008, 2010, 2011, 2015) e não apresenta soluções prontas, receitas teóricas e didáticas a serem implementadas no contexto educacional. Como diz o próprio Morin (2010), o Pensamento Complexo é um desafio ao conhecimento. É um caminho a ser percorrido e construído durante a caminhada levando em consideração as necessidades e especificidades de cada jornada e as múltiplas dimensões que a compõem (social, cultural, emocional, política, econômica) (MORIN, 2010).

Imbernón (2009) corrobora com esta premissa ao afirmar a necessidade da educação e da formação de professores romperem com a linearidade de ideias, concepções e pensamentos, que dificultam, muitas vezes, os profissionais da educação a imaginar outros contextos, estabelecerem relações, fazer conexões e extrapolar as barreiras do conhecimento. O autor ressalta a relevância em "permitir a integração de outras formas de ensinar, de aprender, de organizar-se e, de ver outras identidades sociais, outras manifestações culturais e ouvir-se entre eles e ouvir outras vozes" (IMBERNÓN, 2009, p. 14-15).

Os pressupostos teóricos do Pensamento Complexo podem trazer contribuições para o desenvolvimento de um "novo" olhar ao contexto educacional e à formação de professores na medida em que compreende o ato educativo numa perspectiva de multidimensionalidade, de contextualização e do caráter histórico do conhecimento (SOUZA, 2013). Esta forma de pensar e fazer educação "[...] esforça-se por superar ideias norteadoras que têm promovido à fragmentação e os reducionismos dos saberes, questionar estereótipos cognitivos, verdades estabelecidas, conformismos cognitivos e intelectuais" (SOUZA, 2013, p. 241).

Para Klammer (2011) é fundamental investir na formação de professores, para que em meio à diversidade de fatores e características, presentes na sala de aula, "[...] essa formação contribua para a construção de um pensamento tecido, numa dimensão inovadora e diferenciada que proporcione uma revisão na visão de mundo e de ser humano" (KLAMMER, 2011, p. 123).

Pensar e fazer a docência, sob a ótica de um olhar complexo, pressupõe transformações filosóficas, pedagógicas e didáticas nos processos formativos de professores. Nesta perspectiva, a formação continuada de professores pode contribuir para a compreensão de que a prática docente é um fazer compartilhado, construído cooperativamente entre todos os envolvidos no processo de aprendizagem (professores, estudantes etc.). 
Um programa formativo assim concebido deve priorizar práticas que contemplem a integração indivíduo entre corpo e mente; racionalidade e sensibilidade; ser humano e natureza; favorecendo novas práticas de relações entre as pessoas com vistas a se tornarem mais cooperativas e solidárias (SOUZA, 2013). A instituição educacional pode se tornar algo além de um simples local de atuação docente "[...] passando a ser vista como uma organização complexa encarada como um elemento fundamental para a estruturação do conhecimento" (IMBERNÓN, 2009, p. 109).

Moraes (2007) chama a atenção para a importância dos educadores entenderem que a sua maneira de compreender a realidade, traz consequências metodológicas para a sua prática pedagógica. Os programas formativos, em sua maioria, não preparam os profissionais para saberem lidar com as "emergências" que ocorrem frequentemente nos ambientes de ensino e aprendizagem, o que gera dificuldade de reconhecê-las e de saber lidar com elas.

E em se tratando da utilização das TMDs nas práticas pedagógicas escolares, estas "emergências" se fazem presente quando os professores não se sentem preparados para utilizar pedagogicamente os recursos digitais disponíveis em sua unidade educacional.

Neste sentido, não adianta a formação continuada de professores apresentar aos docentes soluções simplificadas, desconectadas da realidade escolar. É necessário um olhar complexo que abarque uma visão geral das situações existentes em cada contexto escolar e que favoreça a compreensão das inúmeras relações que as permeiam. Assim, os docentes passam a estar mais preparados para lidar com as incertezas e com a diversidade de fatores que envolvem a utilização das tecnologias e mídias digitais nas práticas pedagógicas escolares.

\section{O desenvolvimento da pesquisa}

A pesquisa de abordagem qualitativa configurou-se em um estudo de caso múltiplo desenvolvido em quatro secretarias municipais da educação: de Curitiba e Cascavel, no estado do Paraná, e de Florianópolis e Joinville, no estado de Santa Catarina.

O problema que orientou o processo de investigação buscou identificar, à luz dos pressupostos do Pensamento Complexo, como os programas de formação continuada promovidos pelas Secretarias Municipais da Educação, destinados aos professores, têm contemplado o processo de utilização, integração e apropriação das tecnologias e mídias digitais nas práticas pedagógicas escolares? 
Os objetivos deste estudo corresponderam, de maneira geral, em: caracterizar, descrever, analisar e compreender como se organiza o programa de formação continuada para professores proposto pelas Secretarias Municipais da Educação dos municípios de Curitiba (PR), Cascavel (PR), Florianópolis (SC) e Joinville (SC) em relação ao processo de utilização, das tecnologias e mídias digitais nas práticas pedagógicas escolares.

Os procedimentos metodológicos adotados para a realização do estudo de caso foram: entrevista semiestruturada realizadas com as profissionais das Secretarias Municipais da Educação (SMEs), que ministram a formação continuada em TMDs nas práticas escolares, nos quatro municípios investigados; questionário aplicado aos professores participantes das ações formativas ofertadas pelas SMEs, relacionadas às TMDs nas práticas escolares; e a análise dos documentos oficiais que regem os processos de formação continuada para o processo de utilização das tecnologias e mídias digitais nas práticas escolares das quatro redes municipais de ensino integrantes deste estudo.

A organização, seleção, categorização e análise dos dados da pesquisa ocorreu com a utilização do software Atlas.ti. Os dados foram analisados com base no método de análise de conteúdo proposto por Bardin (2010) e nos estudos do Saldaña (2013), sobre análise de dados qualitativos, tendo como ênfase seus métodos de primeiro e segundo ciclos de codificação.

\section{Principais resultados}

O conjunto de dados analisados na presente pesquisa possibilitou a construção de uma tecitura complexa de proposições para a formação continuada de professores em TMDs, as quais são apresentadas a seguir.

Primeiramente, com relação às questões infraestruturais, a maioria dos professores de Florianópolis e Joinville e a metade dos docentes de Cascavel, indicaram que os recursos digitais utilizados nos espaços de formações e locais de atuação profissional, funcionam adequadamente. Em Curitiba a metade dos professores apontou como adequada a infraestrutura do local de formação e somente $18,5 \%$ dos docentes indicaram que os recursos digitais existentes nas unidades educacionais funcionam adequadamente.

Considera-se que não há como desenvolver um trabalho com as TMDs sem existir uma infraestrutura adequada, principalmente nas unidades educacionais. Os dados desta pesquisa indicam a necessidade de políticas públicas perenes de investimentos para os quatro municípios pesquisados no sentido da manutenção 
de recursos digitais tanto nos locais onde acontece a formação continuada quanto nas unidades educacionais.

Quanto aos documentos oficiais norteadores da prática pedagógica e dos processos formativos (diretrizes/currículo) das quatro SMEs investigadas, constou-se que eles apresentam, em linhas gerais, conceitos de tecnologia relacionados à utilização pedagógica das TMDs, quais sejam: o desenvolvimento de práticas pedagógicas inovadoras; a necessidade de ressignificar os processos de ensino-aprendizagem; a utilização das TMDs no trabalho com os conteúdos dos componentes curriculares; a inserção das TMDs no Projeto Político-Pedagógico de cada unidade educacional; e a inclusão digital de estudantes e professores para a utilização crítica das mídias e para a elaboração e divulgação de conteúdos.

Estes conceitos são fundamentais ao processo educativo. No entanto, não dão conta de compreender a tecnologia em toda a sua Complexidade. Indicase a importância dos documentos norteadores da prática educacional e dos processos de formação continuada docente abarcarem uma concepção complexa de tecnologia. Ou seja, uma concepção que possibilite o entendimento deste conceito em toda a sua multidimensionalidade, como um fenômeno produzido pela humanidade, cultura, sociedade, ciência, educação, economia, política, filosofia etc., compreendendo que, por meio de um processo recursivo, a utilização da tecnologia alimenta, retroalimenta e transforma estes fenômenos.

A tecnologia é um produto do humano, portanto, é um fenômeno multidimensional. A tecnologia enquanto produção humana complexa manifesta suas dimensões: cultural, política, econômica, científica, geracional etc. A tekhne (atividade produtora de artefatos) não apresenta apenas um caráter utilitário, embora esta faceta seja a mais evidente. A tecnologia é criação da inteligência humana (racionalidade sapiens) com a finalidade de estender sua influência e controle sobre a natureza com fins de sobrevivência, de bem-estar, bem como com a intenção de potencializar o poder humano sobre o próprio ser humano. "A técnica é a apropriação prática do mundo e do homem pelo homem. A técnica é exatamente o produto do encontro das participações e da autodeterminação individual" (MORIN, 2020, p. 91).

A tecnologia entendida como fenômeno complexo sempre irá apresentar ambivalência porque é concebida e utilizada pelo ser humano que é sapiens/ demens. A ambivalência indica que o artefato tecnológico sob os auspícios do homo complexus pode ser concebido e utilizado para fins altruístas, bem como para fins egoístas. Conceber a tecnologia à luz do Pensamento Complexo é concebê-la intrínseca às relações humanas. É concebê-la numa trama na qual a dimensão econômica é um aspecto importante (homo faber), porém, não é a única dimensão que constitui a criação, o desenvolvimento e o uso da tecnologia na sociedade e nos processos educativos. A perspectiva teórica da complexidade 
evita "isolar" a tecnologia porque ela é prenhe, é fruto da complexa trama societária que produz a tecnologia num quadro de dimensões que concorrem, antagonizam e se complementam (cultural, científica, política, geracional, histórica etc.), bem como dinamizam a tecnologia capitaneada pelo humano. Os efeitos da tecnologia retroagem sobre a maneira como o humano vive e convive em sociedade. "Doravante aliada à ciência, a técnica é potencialmente transformadora da vida, da sociedade e da natureza" (MORIN, 2001, p. 93).

No que tange ao entendimento de tecnologia por parte das formadoras em TMDs das SMEs elas apresentaram uma concepção atrelada à: utilização do conhecimento científico para a produção de recursos; aos instrumentos e às matérias-primas; às tecnologias simbólicas (linguagem, pensamento, escrita e representações icônicas); aos processos que estão presentes em tudo o que envolve a criação realizada pelo homem e que influenciam a aprendizagem e o comportamento das pessoas para melhorar as condições de vida humana; às ferramentas, artefatos ou equipamentos construídos para a realização de tarefas. Estes apontamentos conceituais, indicados pelas formadoras dos quatro municípios investigados, podem contribuir para a construção da concepção de tecnologia dos docentes participantes das formações.

A concepção de caráter instrumental, presente na maioria dos relatos dos professores participantes da pesquisa pode dificultar a integração das TMDs na prática pedagógica na medida em que não compreendem a tecnologia como um fenômeno multidimensional (humano, cultural, social, científico, econômico, filosófico, político etc.), mas à luz de uma concepção pragmática e utilitária. É de suma importância ao processo de utilização pedagógica das TMDs, que os programas de formação continuada de professores desenvolvam uma concepção de tecnologia para além de um conceito meramente instrumental, favorecendo a concepção complexa de tecnologia (tecida, religada, contextualizada, multidimensional e recursiva).

Neste sentido, identifica-se a necessidade dos programas de formação continuada promoverem ações pertinentes para que a tecnologia passe a ser compreendida pelas formadoras e professores como um processo recursivo que abrange um conjunto de: saberes, conhecimentos, ideias e pensamentos que dão origem a novas descobertas e se concretizam em novas soluções, metodologias, produtos, linguagens, ferramentas e mediações que têm por objetivo facilitar e melhorar a vida das pessoas e contribuir para o desenvolvimento da sociedade.

Identifica-se a necessidade de os programas de formação continuada promoverem um conhecimento pertinente sobre a concepção de tecnologia a partir da epistemologia da complexidade. Um conhecimento pertinente aponta para a necessidade de situar, contextualizar, conceber a multidimensionalidade do fenômeno tecnológico e suas implicações ambivalentes, contraditórias 
e complementares na trama societária. Morin (1997, p. 92) diz que: “[...] a técnica abre o mundo para o homem e o homem para o mundo [...] o mundo penetra nele, e o enriquece" E ainda complementa: “[...] assim transformado, o homem transforma o mundo, lhe dá as determinações humanas, o humaniza". A tecnologia é produto do homo complexus, o que implica concebê-la como uma extensão e uma manifestação técnica, mas também, cultural, histórica, política, pedagógica, científica etc. Uma concepção complexa sobre a tecnologia implica sempre pensar seu uso, seu manuseio, sua integração aos conteúdos curriculares dentro de um contexto social, econômico, cultural, político, educacional, bem como os efeitos decorrentes do seu manuseio uso e integração ao conteúdos retroagem, condicionando novos modos de (re)construir conhecimento, de adquirir habilidades e competências, diante do contexto contemporâneo cibercultural. Uma concepção complexa compreende a técnica e a ciência num entrelaçamento que resulta numa tecnologia cada vez mais "inteligente" e, aquela, que pode se revestir enquanto mediação (ambivalente) para diversos e diferentes finalidades sob uma racionalidade aberta (MORIN, 2020), tendo potencialmente o papel de contribuir para o desenvolvimento social (econômico, cultural, educacional, político etc.), para a formação humana, para o acesso e a democratização do conhecimento, bem como para o bem estar da humanidade.

Quanto ao desenvolvimento das formações, os dados revelaram a importância de as ações formativas acontecerem in loco, na unidade escolar, ou seja, formações em contexto, a fim de atenderem às demandas específicas dos professores de maneira conectada, articulada, imbricada com a sua realidade educacional. Menciona-se mais uma vez as contribuições de Nóvoa (1992; 2013), Imbernón (2009; 2010) e Prado e Valente (2003), ao afirmarem que as formações desenvolvidas em contextos generalistas (fora do contexto escolar) muitas vezes são desconexas da realidade educacional e apresentam características de transmissão normativa e aplicativa, ao invés de acompanhamento do processo de transformação da prática. De acordo com estes autores este formato de formação não contribui para promover mudanças e nem inovações nas ações pedagógicas dos professores.

Recomenda-se aos programas de formação continuada em TMDs o desenvolvimento da formação in loco, na unidade de atuação docente. A formação em contexto possibilita que os conteúdos das formações estejam em consonância com os recursos digitais disponíveis em cada unidade educacional. Desta forma, busca-se acabar com a incoerência de não existir, nos espaços de atuação dos professores, as mesmas TMDs que utilizam nos locais de formação das SMEs (laboratórios de informática ou salas e ambientes com recursos digitais), o que, muitas vezes, impossibilita colocar em prática no seu trabalho de sala de aula os conteúdos das formações. 
A pesquisa revelou a preocupação e a intenção por parte das formadoras das quatro SMEs investigadas em atenderem aos interesses, às necessidades e às expectativas dos professores participantes das formações em TMDs. De acordo com mais de $50 \%$ destes docentes, os processos formativos estão em consonância com o que esperam e desejam da formação continuada em TMDs.

Estes dados são significativos, no entanto, cabe reiterar que, de acordo com Nóvoa (1992, 2013), Imbernón (2009, 2010) e Gatti; Barreto (2009), os programas de formação continuada, para além de atenderem aos interesses, necessidades, e expectativas dos professores, precisam propiciar uma maior atuação dos docentes em seus processos formativos. Isso requer, oportunizar a participação e tomada de decisão, dos professores, desde o planejamento até a implementação das ações formativas. Segundo estes autores estas medidas são necessárias para a promoção de mudanças positivas/qualitativas no contexto educacional.

Sugere-se, portanto, que os programas de formação continuada em TMDs, desenvolvam nos seus processos formativos o protagonismo docente, o qual configura-se por meio de ações que estão além de ouvir as necessidades, interesses e expectativas docentes. Este protagonismo, de acordo com os pressupostos teóricos do Pensamento Complexo deve favorecer a reintrodução do sujeito cognoscente. Ou seja, proporcionar ao professor a participação ativa no seu processo de formação, com a possibilidade de apresentar sugestões e contribuições (teóricas e práticas), além de ter "voz de decisão" desde o momento do planejamento, até na organização, implementação, avaliação e readequação das ações formativas das quais participa.

Os dados alcançados com este estudo também revelaram que as formações em TMDs ainda não acontecem de maneira articulada com outros departamentos e setores das SMEs. O que vem ocorrendo são ações incipientes e pontuais de tentativas de integração entre os setores.

Perpetua-se ainda o desenvolvimento de ações estanques e fragmentadas nos processos formativos que não possibilitam o entendimento de como integrar as TMDs no trabalho com os conteúdos dos diferentes componentes curriculares, uma vez que as próprias formações não contemplam esta integração. Neste sentido, a pesquisa apontou a necessidade de elaborar-se uma formação continuada de professores sob uma perspectiva complexa que possibilite uma efetiva religação dos saberes que são trabalhados nas formações de tal sorte que haja uma compreensão contextualizada do conhecimento.

A partir dos resultados obtidos foi possível considerar que devido à multiplicidade de fatores, situações e demandas que regem o contexto educacional, como, por exemplo: o número excessivo de estudantes em sala de aula (30 a 35 estudantes); a demanda grande de trabalho (planejamento; elaboração e preparo de materiais; a prática de sala de aula (preparar, aplicar e 
corrigir avaliações, estudos, formações etc.); os estudantes com deficiências e dificuldades de aprendizagem; a diversidade de projetos a serem implementados na escola; os problemas de infraestrutura que acarretam problemas técnicos na hora de utilizar estes recursos com os estudantes; entre outros, os professores precisam de auxílio, de acompanhamento e de assessoramento pedagógico no momento que irão implementar suas práticas pedagógicas utilizando TMDs.

De acordo com esta pesquisa, nos municípios de Curitiba e Cascavel o acompanhamento/assessoramento pedagógico pós-formação ainda não acontece, por outro lado, em Florianópolis e Joinville este acompanhamento ocorre como uma prática constante e inerente ao trabalho das formadoras das SMEs.

O acompanhamento/assessoramento pode ser praticado por um professor de tecnologia ou integrador de mídias (como Joinville, Florianópolis e Cascavel já possuem); pela equipe diretiva e pedagógica; por um profissional da Secretaria de Educação, específico para esta atividade; e por professores atuantes em universidades parceiras. A presença constante destes profissionais no contexto escolar justifica-se pela necessidade de auxiliarem os professores: a) na implementação das práticas pedagógicas com a utilização das TMDs; b) para acompanharem e assessorarem os docentes a colocarem em prática os conteúdos desenvolvidos nas formações; c) e, também, para promoverem formação continuada em TMDs no local de atuação dos professores.

Outro dado revelado neste estudo é o de que a maioria dos professores participantes da pesquisa nos municípios de Curitiba, Florianópolis e Joinville, bem como a metade dos docentes de Cascavel, já utilizou (ao menos uma vez) recursos digitais com os estudantes. De acordo com estes profissionais, a utilização pedagógica das TMDs: contribui para motivar e despertar o interesse dos estudantes durante os encaminhamentos de sala de aula; possibilita uma maior diversidade de recursos e encaminhamentos didáticos a serem utilizados com os estudantes; contribui para o desenvolvimento do processo de ensino-aprendizagem.

Estes indicativos apontam para uma aceitação e uma pré-disposição destes profissionais em utilizarem as TMDs em suas práticas pedagógicas escolares. Fator importante para que estes recursos sejam integrados ao contexto escolar como práticas constantes e inerentes ao trabalho pedagógico. E denotam também a clareza por parte dos professores dos aspectos contributivos que a utilização pedagógica das TMDs pode promover no processo educacional.

Este é um aspecto relevante que precisa ser observado com atenção pelos programas de formação continuada das SMEs, uma vez que se os professores reconhecem a importância da integração pedagógica das TMDs, e estão prédispostos a promoverem esta integração em suas ações educacionais, assim, é fundamental a intensificação de ações formativas que subsidiem este processo. 
No desenvolvimento da pesquisa foi constatando que as principais contribuições da formação continuada, apontadas pelas formadoras das quatro SMEs e pelos professores participantes da pesquisa, estão relacionadas a: subsidiar teórica e metodologicamente os professores na utilização pedagógica das TMDs; auxiliar na integração curricular destes recursos; e orientar a utilização das TMDs no desenvolvimento de conteúdos e atividades dos diferentes componentes curriculares.

Observou-se, por meio deste estudo que esta preocupação das formadoras em disseminar a importância e a necessidade da utilização pedagógica das TMDs, já está resultando em ações concretas na prática docente das quatro SMEs investigadas. De acordo com as formadoras, a partir dos processos formativos, os professores já desenvolveram ou desenvolvem atividades pedagógicas que contemplam: produção de vídeos e animações; elaboração de jornal digital; construção de histórias em quadrinhos; trabalhos com linguagem de programação; realização de pesquisas; produção de textos; uso de sites e softwares educacionais, dentre outras ações.

Apesar destas atividades, muitas vezes acontecerem em momentos pontuais e estanques ou desenvolvidas em forma de projeto (com data para início e término), já podem ser consideradas como um importante passo para a efetivação do processo de utilização das TMDs na prática pedagógica.

É importante ressaltar que o olhar atento, reflexivo e complexo (multidimensional e recursivo) sob as ações envolvendo as TMDs que já se consolidam no contexto educacional, pode apresentar indícios contributivos para aprimorá-las, reconstruí-las, ressignificá-las, produzir novas ações e apontar caminhos para o desenvolvimento de práticas constantes e perenes de utilização pedagógica das TMDs no processo educacional.

O estudo também permitiu identificar quais são os principais motivos, de acordo com a percepção das formadoras das SMEs, para a não utilização das TMDs por parte dos docentes dos quatro municípios investigados. Dentre eles destacam-se: a insegurança do professor e falta de conhecimento de como utilizar pedagogicamente os recursos tecnológicos digitais; a necessidade de intensificar a formação continuada em TMDs; os problemas de infraestrutura; e a falta de apoio do gestor escolar e da equipe pedagógica na implementação de projetos que envolvam as tecnologias e mídias digitais.

Estas informações são relevantes e precisam ser consideradas e compreendidas sob a óptica da Complexidade pelas SMEs. Perspectiva esta, capaz de acolher e compreender as incertezas, as inseguranças, os acertos e erros que envolvem a prática educacional. E que considere o professor como sujeito cognoscente do processo educativo. Ou seja, que a sua "voz" e sua participação 
efetiva nos programas de formação continuada, podem trazer importantes contribuições para a utilização das TMDs nas práticas pedagógicas escolares.

A partir do desenvolvimento da pesquisa, constatou-se a importância de a formação continuada de professores tornar-se o "carro chefe" da ação políticopedagógica de toda Secretaria Municipal da Educação. As mudanças que se almejam conquistar no contexto educacional começam a ser implementadas a partir da formação docente, pautadas no protagonismo dos professores e estudantes.

O olhar complexo que permeou os estudos da pesquisa, possibilitou a compreensão de que para que a formação continuada de professores em TMDs possa trazer contribuições para a prática pedagógica é importante levar em consideração: a necessidade de uma concepção pedagógica que contemple os pressupostos teóricos do Pensamento Complexo; o protagonismo docente; infraestrutura adequada; formação em contexto; acompanhamento da prática pedagógica; e auxílio na utilização das TMDs.

Compreende-se, portanto, a necessidade de uma nova pedagogia que possa ressignificar as formações continuadas de professores em TMDs. A luz dos pressupostos teóricos do Pensamento Complexo é possível construir processos formativos que contemplem novas formas de ensinar e aprender; que estejam em constante processo de construção e reconstrução; que concebam os estudantes, os professores e demais profissionais da educação em suas múltiplas dimensões (cultural, social, cognitiva, afetiva etc.); que ensine, pratique e vivencie a compreensão humana sob uma perspectiva ética e solidária; que dissemine a premência de uma concepção global/local sobre a identidade terrena; que perceba a necessidade de lidar com os fatos, eventos e fenômenos e suas indeterminações, as quais fazem parte dos processos tecnológicos, culturais, científicos, midiáticos, políticos e educacionais. Ensinamentos tão necessários e urgentes nos dias atuais.

Destaca-se a importância de um olhar complexo, de uma nova pedagogia pautada nos pressupostos teóricos do pensar complexo que possa subsidiar os órgãos educacionais (secretarias, departamentos, coordenações etc.) a compreenderem que a formação continuada de professores em TMDs não é um fenômeno isolado, instrumental e estanque. Mas que necessita de uma concepção que "costure" como uma tapeçaria os múltiplos fatores que compõem o processo educativo para que tragam contribuições efetivas ao contexto educacional.

Considera-se a relevância de políticas públicas voltadas a promoverem uma formação continuada de qualidade e a realizarem investimentos contínuos na aquisição e manutenção de recursos digitais a serem utilizadas no processo de ensino-aprendizagem dos estudantes. Políticas estas que sejam perenes, com ações e investimentos no campo educacional que não se desfaçam, nem sejam abandonadas a cada mudança de gestão governamental. 
Entende-se que numa perspectiva pedagógica complexa, a importância da comunidade escolar e, sobretudo, os pais acompanharem e garantirem enquanto sociedade, que as conquistas na qualidade da educação pública constituem-se um patrimônio de todos/as e que não devem e não podem desaparecer quando uma gestão municipal termina. A manutenção da educação pública passa por uma nova cultura, por uma nova prática social que acolha e compartilhe com a comunidade interna e externa da escola, suas conquistas e a manutenção da qualidade do ensino oferecido à sociedade.

\section{Considerações finais}

Ao finalizar, deseja-se que este estudo e que os indicadores e os apontamentos aqui apresentados, tragam contribuições para que os diversos órgãos educacionais, bem como aos programas de formação continuada de professores para a utilização pedagógica das tecnologias e mídias digitais. Deseja-se, ainda, que possam contribuir para a implementação ações didáticopedagógicas que proporcionem um processo de ensino-aprendizagem de qualidade, favorecendo o protagonismo de educadores e educandos, bem como possibilitando condições necessárias para que os professores possam exercer dignamente a profissão docente.

\section{REFERÊNCIAS}

ALMEIDA, Maria Elizabeth Bianconcini de; VALENTE, José Armando. Tecnologias e currículo: trajetórias convergentes ou divergentes? São Paulo: Paulus, 2011.

BARDIN, Laurence. Análise de conteúdo. Lisboa: Edições 70, 2011.

BELLONI, Maria Luiza. A televisão como ferramenta pedagógica na formação de professores. Revista Educação e Pesquisa, São Paulo, v. 29, n. 2, p. 287-301, jul./dez. 2003.

BELLONI, Maria Luiza. Mídia-educação: contextos, histórias e interrogações. In: FANTIN, Mônica; RIVOLTELLA, Pier Cesare (org.). Cultura Digital e escola: pesquisa e formação de professores. Campinas, SP: Papirus, 2012. p. 31-56 
BRASIL. Lei $\mathrm{n}^{\circ}$ 9.394, de 20 de dezembro de 1996. Estabelece as diretrizes e bases da educação nacional. Diário Oficial da República Federativa do Brasil, Brasília, 23 dez. 1996.

BRASIL. Ministério da Educação. Conselho nacional de Educação. Resolução $n^{\circ} 2$, de 1 de junho de 2015. Diretrizes Curriculares Nacionais para a formação inicial em nível superior (cursos de licenciatura, cursos de formação pedagógica para graduados e cursos de segunda licenciatura) e para a formação continuada. Brasília, DF: MEC, 2015

FANTIN, Mônica; RIVOLTELLA, Pier Cesare (org.). Cultura Digital e escola: pesquisa e formação de professores. Campinas, SP: Papirus, 2012.

FREIRE, Paulo. Pedagogia do oprimido. 38. ed. Rio de Janeiro: Paz e Terra, 2004.

FREITAS, Maria Teresa de Assunção. A formação de professores diante dos desafios da cibercultura. In: FREITAS, Maria Teresa de Assunção (org.). Cibercultura e formação de professores. Belo Horizonte: Autêntica, 2009. p. 57-74.

GATTI, Bernadete Angelina; BARRETO, Elba Siqueira de Sá. Professores do Brasil: impasses e desafios. Brasília: UNESCO, 2009.

GREEN, Hannah; HANNON, Celia. Their Space: education for a digital generation. Londres: Demos, 2007.

IMBERNÓN, Francisco. Formação permanente do professorado: novas tendências. São Paulo: Cortez, 2009.

IMBERNÓN, Francisco. Formação continuada de professores. Porto alegre: Artmed, 2010.

KENSKI, Vani Moreira. Educação e Tecnologias: o novo ritmo da informação. 8. ed. Campinas, SP: Papirus, 2012.

KENSKI, Vani Moreira. Tecnologias e tempo docente. Campinas, SP: Papirus, 2013.

KLAMMER, Celso Rogério. Formação continuada para a prática docente no paradigma da complexidade com o uso das tecnologias da informação e comunicação. Orientadora: Marilda Aparecida Behrens 2011. 303 f. Tese (Doutorado em Educação) - Pontifícia Universidade Católica do Paraná, Curitiba, 2011.

LEMOS, André. Cibercultura: tecnologia e vida social na cultura contemporânea. 5. ed. Porto Alegre: Sulina, 2013.

MORAES, Maria Cândida. A formação do educador a partir da complexidade e da transdisciplinaridade. Diálogo Educ., Curitiba, v. 7, n. 22, p. 13-38, set./dez. 2007.

MORAES, Maria Cândida. Complexidade e currículo: por uma nova relação. Polis, Revista de la Universidad Bolivariana, Santiago, Chile, v. 9, n. 25, p. 289-311, 2010.

MORIN, Edgar. O homem e a morte. Tradução de Cleone Augusto Rodrigues. Rio de Janeiro: Imago, 1997. 
MORIN, Edgar. Ciência com consciência. Tradução de Maria D. Alexandre e Maria Alice Sampaio Dória. 5. ed. Rio de Janeiro: Bertrand, 2001.

MORIN, Edgar. Introdução ao pensamento complexo. 5. ed. Lisboa: Instituto Piaget, 2008.

MORIN, Edgar. Meu caminho: entrevistas com Djénane Kareh Tager. Rio de Janeiro: Bertrand Brasil, 2010.

MORIN, Edgar. Os sete saberes necessários à educação do futuro. 2.ed. São Paulo: Cortez; Brasília, DF: UNESCO, 2011.

MORIN, Edgar. A cabeça bem feita: repensar a reforma, reformar o pensamento. 22 ed. Rio de Janeiro: Bertrand Brasil, 2015.

MORIN, Edgar. A aventura de O Método e para uma racionalidade aberta. Tradução de Edgard de Assis Carvalho e Mariza Perassi Bosco. São Paulo: Edições Sesc/São Paulo, 2020.

NOVOA, Antônio (org.). Profissão Professor. 2 ed. Portugal: Porto, 1999. (Coleção Ciências da Educação).

NOVOA, Antônio. Nada substitui um bom professor: propostas para uma revolução no campo da formação de professores. In: GATTI, Bernadete Angelina et al. Por uma política nacional de formação de professores. São Paulo: Unesp, 2013. p. 199-210.

OFCOM. Media Literacy Audit: report on adult media literacy. Londres: OFCOM, 2006. Disponível em: https://www.ofcom.org.uk/research-and-data/media-literacy-research/ adults /medialit_audit. Acesso em: 01 nov. 2020.

PETRAGLIA, Izabel Cristina. Complexidade e auto-ética. EccoS Rev. Cient., São Paulo, v. 2, n. 1, p. 9-17, jun. 2000.

PRADO, Maria Elisabette Brisola Brito; VALENTE, José Armando. A formação na ação do professor: uma abordagem para uma nova prática pedagógica. In: VALENTE, José Armando (org.). Formação de educadores para o uso da informática na escola. Campinas: UNICAMP/NIED, 2003. p. 21-38.

SACRISTAN José Gimeno. Poderes instáveis em educação. Porto Alegre: Artmed, 1999.

SALDAÑA, Johnny. The coding manual for qualitative researchers. London: SAGE Publications Ltd., 2013.

SOUZA, Ruth Catarina Cerqueira Ribeiro de. Formação de professores: tempos de vidatempos de aprendizagem. In: SANTOS, Akiko; SUANNO, João Henrique; SUANNO, Marilza Vanessa Rosa (org.). Didática e formação de professores: complexidade e transdisciplinariedade. Porto Alegre: Sulina, 2013. p. 239-262.

VALENTE, José Armando. Formação de educadores para o uso da informática na escola. Campinas, SP: UNICAMP, 2001. 
VALENTE, José Armando. As tecnologias e as verdadeiras inovações na educação. In: ALMEIDA, Maria Elizabeth Bianconcini de; DIAS, Paulo; SILVA, Bento Duarte da (org.). Cenários de inovação para a educação na sociedade digital. São Paulo: Edições Loyola, 2013. p. 35-46.

VOSGERAU, Dilmeire S. R. Reconception d'une formation à l'intégrationdes TIC à l'enseignementà partir de l'analyse d'une pratique, de sés fonctionnalités et de sés dysfonctions. 2005. Thèse (Grade de Philosophie Docteur) - Université de Montréal, Montréal, 2005.

Texto recebido em $07 / 04 / 2020$.

Texto aprovado em 26/11/2020. 